\title{
Predicting the Presence of an Accessory Hepatic Vein Using Abdominal Computed Tomography
}

\author{
Predicción de la Presencia de una Vena Hepática Accesoria \\ Mediante Tomografía Computarizada Abdominal
}

Hyung Soo Kim; Chang Hee Lee²; Seong Hyun Kim²; Jeong Woo Kim²; Cheol Min Park² \& Suk Keu Yeom

KIM, H. S.; LEE, C. H.; KIM, S. H.; KIM, J. W.; PARK, C. M. \& YEOM, S. K. Predicting the Presence of an accessory hepatic vein using abdominal computed tomography. Int. J. Morphol., 35(1):21-25, 2017.

SUMMARY: The incidence of detection of accessory hepatic vein (AHV) using MRI or CT has been reported. However, previous studies had a small sample size or only reported on the incidence of hepatic vein variants. To the best of our knowledge, there has been no previous report evaluating the factors predictive of the presence of an AHV. To evaluate the incidence and morphology of the accessory hepatic vein (AHV) using multidetector row computed tomography (MDCT) and to investigate the factors which may be helpful in predicting the presence of an AHV. We enrolled 360 patients who underwent abdominal MDCT. We investigated whether the AHV was present and evaluated the frequency of AHVs greater than $5 \mathrm{~mm}$ in diameter. We classified the morphology of the AHV entering the inferior vena cava (IVC). We also examined the factors that predicted the presence of an AHV by comparing the diameter of the middle hepatic vein (MHV) and the right hepatic vein (RHV). We identified an AHV in 164 of the 360 patients (45.6\%). Among the 164 AHVs, $56.7 \%$ were larger than $5 \mathrm{~mm}$ in diameter. The most common morphologies of the inferior RHV were a single main trunk $(58.5 \%)$, followed by two main trunks with a V-shape (19.5\%) and two trunks entering the IVC separately (17.0\%). The possibility that an AHV will be present was significantly higher when the diameter of the RHV was smaller than that of the MHV. MDCT can provide important information regarding AHV incidence and morphology. The possibility of an AHV being present was significantly higher when the diameter of the RHV was smaller than that of the MHV.

KEY WORDS: Accessory hepatic vein; MDCT; Liver; Hepatic vein.

\section{INTRODUCTION}

In addition to the major hepatic veins, the accessory hepatic vein (AHV) is a hepatic venous branch entering the right side of the inferior vena cava (IVC). Due to the recent increase in living donor liver transplantation, the AHV has become one of the most important variants for both donors and recipients (Orguc et al., 2004). The presence of a large AHV sometimes requires a longer operating time and modifications to the surgical approach and technique (Erbay et al., 2003). Accurate preoperative imaging to evaluate the AHV is essential for surgical planning and has been shown to minimize mortality and morbidity (Inomata et al., 2000; Pomfret et al., 2001; Guiney et al. 2003).

The incidence of detection of AHV using MRI or CT has been reported (Ng et al., 1990; Cha et al. 1995; Erbay et al.; Guiney et al.; Orguc et al.). However, previous studies had a small sample size or only reported on the incidence of hepatic vein variants. To the best of our knowledge, there has been no previous report evaluating the incidence, morphologic classification of the AHV, or the factors predictive of the presence of an AHV, using multidetector row computer tomography (MDCT). Due to improved spatial, contrast, and temporal resolution of MDCT, small blood vessel branches can be assessed more accurately. We expected that the incidence and morphology of the AHV could be evaluated more accurately using MDCT.

The purpose of this study was to evaluate the incidence of AHV using MDCT, classify the morphologies, and investigate the factors that may help predict the presence of an AHV by examining the relationship between the presence of an AHV and the diameters of the right hepatic vein (RHV) and middle hepatic vein (MHV).

${ }^{1}$ Department of Radiology, Sanbon Hospital, Wonkwang University College of Medicine.

${ }^{2}$ Department of Radiology, Korea University Guro Hospital, Seoul, Korea

${ }^{3}$ Department of Radiology, Korea University Ansan Hospital, Ansan-si, Korea 


\section{PATIENTS AND METHOD}

Patients. We enrolled 360 consecutive patients who had undergone multiphase abdominal CT at the tertiary university Hospital between December 2012 and January 2014 in this retrospective study. Patients with liver cirrhosis or hepatocellular carcinoma were excluded because of concern that the liver parenchyma surrounding the AHV might be distorted. The patient group included 185 men and 175 women with a mean age of 52 years (range, 21-87 years).

CT technique. A 16-channel MDCT scanner (Siemens, Erlargens, Germany) was used to perform multiphase image acquisition after intravenous bolus administration of $120 \mathrm{cc}$ of non-ionic contrast material at a rate of $3 \mathrm{cc} / \mathrm{s}$. The scanning parameters were as follows: collimation of $0.75 \mathrm{~mm}$ with a table speed of $10 \mathrm{~mm} / \mathrm{s}, 120 \mathrm{kVp}$, and 150-200 mA. The scanning delay after initiation of the contrast bolus injection was $12 \mathrm{sec}$ for the hepatic arterial phase, $75 \mathrm{~s}$ for the portal venous phase, and $180 \mathrm{~s}$ for the delayed phase.

Axial CT scans were reconstructed using a standard algorithm, and post-processing was performed using a commercially available workstation.

Image analysis. All images were analyzed by consensus of two radiologists. All images were reviewed using the full PACS view program (II view; INFINIT, Seoul) and the veins were measured using a $700 \%$ enlarged image in the embedded software. Axial scans were reviewed and delayed phase images that best depicted the hepatic veins were analyzed. We evaluated all of the patients for the presence of an AHV. If an AHV was present, we measured the largest diameter near the AHV-caval confluence. We also calculated the percentage of patients with an AHV greater than $5 \mathrm{~mm}$ in diameter. We classified the morphology of the venous drainage into the IVC by assessing the number of main trunks or tributaries from the main trunk. After we measured the largest diameter of RHV and MHV near the RHV/MHVcaval confluence, we compared the diameter of the RHV and MHV between patients with and without an AHV.

We hypothesized that patients with a RHV that was smaller than the MHV would be more likely to have an AHV and that this could be used as a predictor for the presence of an AHV.

Statistical analysis. We used the Student's t-test to compare the difference in the diameters of the MHV and the RHV between patients with and without an AHV. A receiver operating characteristic (ROC) curve analysis was used to determine the cut-off value for the MHV/RHV ratio that presented the best combination of sensitivity and specificity for distinguishing the presence or absence of an AHV. A p value of $<0.05$ indicated a statistically significant difference.

\section{RESULTS}

Among the 360 patients, we found an AHV in 164 patients (45.6\%). In these 164 patients, $93(56.7 \%)$ had AHVs that were larger than $5 \mathrm{~mm}$ in diameter. The average length of the AHV was $6.4 \mathrm{~mm}$ (range, 1-13.1 mm). The schematic illustration of the morphologic AHV classification is shown in Fig. 1. All of the AHVs were located in the posteroinferior portion of the right hepatic lobe. The most common type of inferior RHV (IRHV) was a single main trunk entering the IVC without tributaries that was seen in $58.5 \%(96 / 164)$ of the patients (Fig. 2). Two main trunks


A
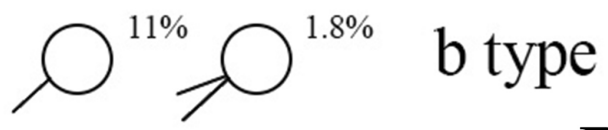

B

Fig. 1. The anatomy of accessory hepatic vein and schematic diagram of variations of accessory hepatic vein. A. The schematic drawing of inferior right hepatic vein (IRHV) and middle right hepatic vein (MRHV). *RHV: Right hepatic vein, MHV: Middle hepatic vein, LHV: Left hepatic vein. B. Variations of inferior right hepatic vein (a type) and middle right hepatic vein (b type). 
with a V-shape at the IRHV-caval confluence were seen in $19.5 \%(32 / 164)$ (Fig. 3A) of the patients. Other variations included two main trunks entering the IVC with a small tributary at the lower trunk in $1.2 \%(2 / 164)$ (Fig. 3B); two trunks entering the IVC separately in $17 \%$ (28/164) (Fig.

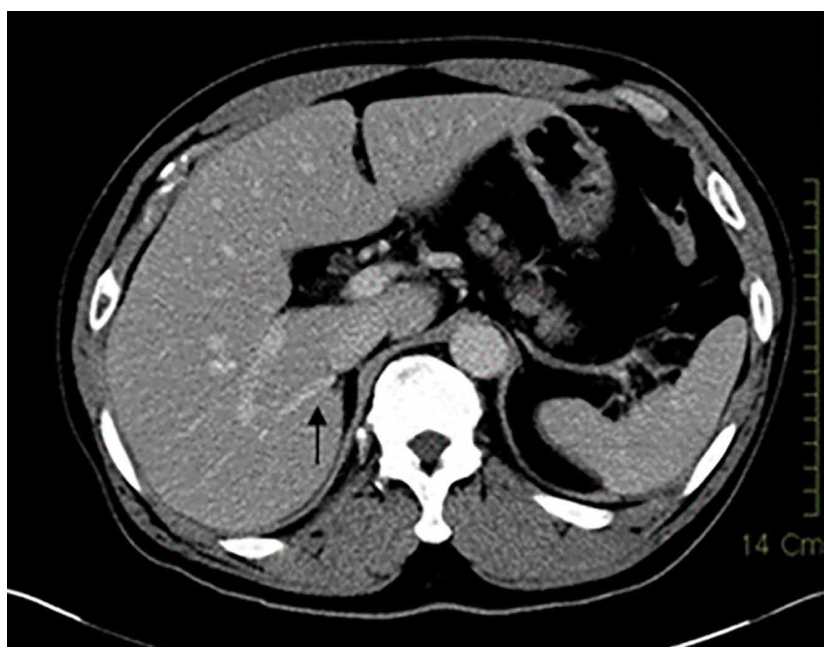

Fig. 2. 51-year-old man. Axial portal venous phase CT scan shows a linear shape of inferior right hepatic vein (arrow) that drains to inferior vena cava.
$3 \mathrm{C})$; two separate trunks with a tributary at the lower trunk in $3 \%(5 / 164)$ (Fig. 3D); and two separate trunks with a tributary at the upper trunk in $0.6 \%(1 / 164)$ of the patients.

The middle RHV (MRHV), another hepatic vein variant, located between the RHV and the IRHV was seen in 22 patients. These variants appeared within $2 \mathrm{~cm}$ of the IRHV-caval confluence and appeared only when an IRHV was present. The morphological types of these variants were a single main trunk $(\mathrm{n}=18)$, a main trunk with tributaries $(\mathrm{n}$ $=3$ ) and other $(n=1)$ (Fig. 3E, F).

The average and standard deviation of the MHV/RHV ratio was $1.08 \pm 0.28$ (range, $0.5-1.67$ ) for the group with an AHV and $0.81 \pm 0.19$ (range: 0.43-1.41) for the group without an AHV. The average of the ratio was significantly higher in the group with an AHV $(\mathrm{p}<0.0001)$. The area under ROC curve was 0.804 . When the cut-off value of the $\mathrm{MHV} / \mathrm{RHV}$ ratio was 1 , the best combination of sensitivity $(85 \%)$ and specificity (65\%) was provided (Fig. 4). The odds ratio for AHV was 8.05 (95\% confidence interval, 4.95-13.09) when MHV/RHV > 1 was compared to MHV/ RHV $<1(\mathrm{p}<0.0001)$.
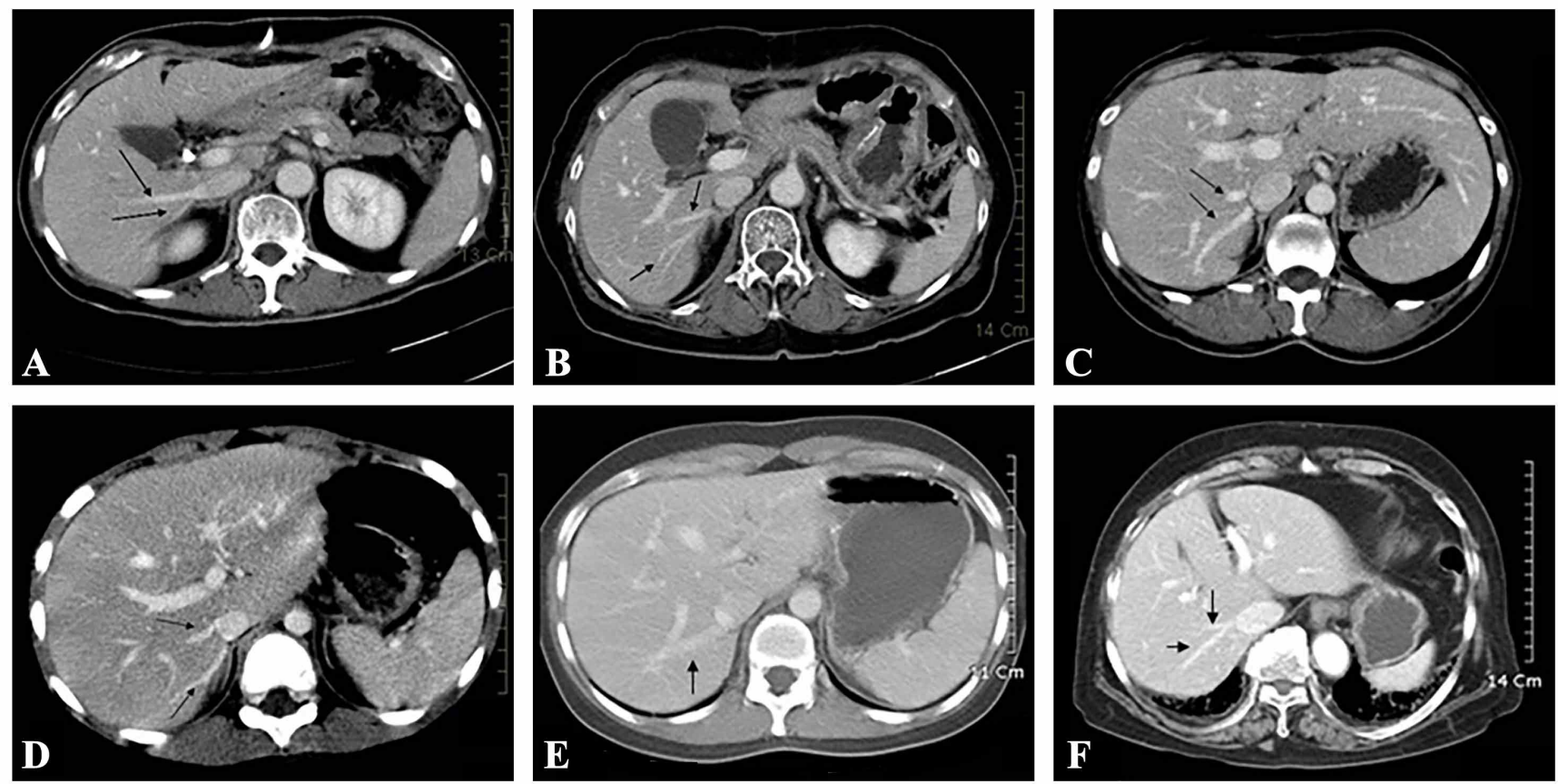

Fig. 3. A. 57-year-old woman. Axial portal venous phase CT scan shows V-shape type of inferior right hepatic vein (arrows) that drains to inferior vena cava. B. 62-year-old woman. Other V-shape type of inferior right hepatic vein (arrows) is located at posteroinferior portion of the right lobe of liver. C. 33-year-old woman. Axial portal venous phase CT scan shows the parallel draining type of inferior right hepatic vein (arrows) that drains to inferior vena cava. D. 8-year-old man. Other parallel draining type of inferior right hepatic vein (arrows) is located at posteroinferior portion of the right lobe of liver. E - F. Variations of middle right hepatic vein. E. 35-year-old woman. Axial portal venous phase CT scan shows a linear type of middle right hepatic vein (arrow) that drains to inferior vena cava. F. 73-year-old woman. Axial portal venous phase CT scan shows V-shaped type of middle right hepatic vein (arrows) that drains to inferior vena cava. 


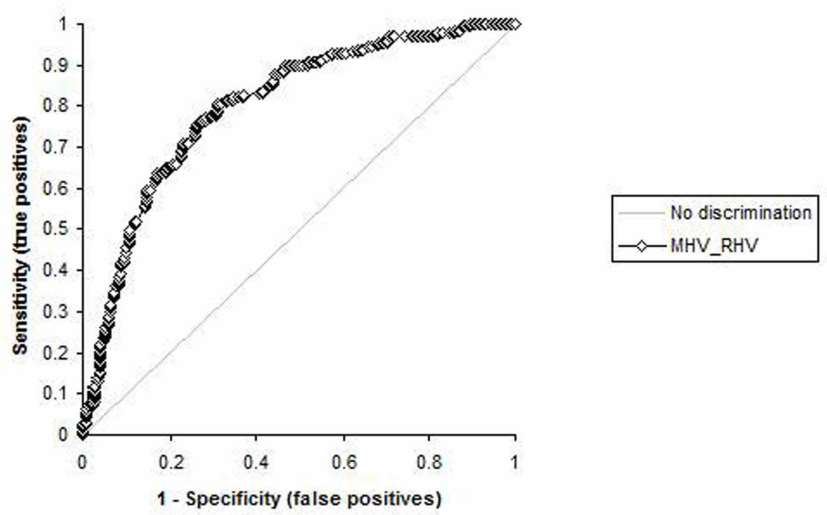

Fig. 4. The ROC curve for MHV/RHV ratio between the group with AHV and group without AHV. The area under ROC curve was 0.804 . When the cut-off value of the MHV/RHV ratio was 1 , the best combination of sensitivity $(85 \%)$ and specificity $(65 \%)$ was provided

\section{DISCUSSION}

The demand for liver transplantation has recently increased in spite of the limited availability of cadaveric livers and has resulted in a gradual increase of living donor liver transplantation (Erbay et al.). Preoperative knowledge of the hepatic vascular anatomy is essential to the transplantation surgeon (Guiney et al.). One of the most important hepatic vascular variants is the AHV which is a hepatic venous branch entering the right side of the IVC in addition to the major hepatic veins. The AHV consisting of IRHV and MRHV is a common variant and is important for both donors and recipients, but more so for the donors (Erbay et al.). Before surgery, it is important to know if an AHV is present. The size of the AHV is especially important because it can affect the surgical approach. If the diameter of the $\mathrm{AHV}$ is greater than $5 \mathrm{~mm}$, the vessel has to be preserved and re-anastomosed to the recipient's IVC (Erbay et al.; Guiney et al.; Orguc et al.) otherwise it can lead to a congested graft and consequently to organ rejection (Marcos et al., 2000). Other important aspects of the AVH are as follows: (i) segment six can be preserved through the thick IRHV drainage to the IVC even when the entire RHV is resected during lobectomy, (ii) IRHV thrombosis can be observed in hepatocellular carcinoma, and (iii) most of the hepatic venous drainage in primary Budd-Chiari syndrome passes through the IRHV (Makuuchi et al., 1983). In this study, we evaluated the incidence, morphologic types of the IRHV and MHV entering the IVC, and proposed factors predicting the presence of an AHV.

The presence of an AHV has been reported using a variety of imaging modalities. According to Orguc et al., an
AHV was present in $47 \%$ of the living liver donors examined (47/100). Erbay et al. found 33 of 70 people with an AHV using MDCT (47.1\%) and Guiney et al. reported the presence of an AHV in 40 of 100 potential liver donors using MDCT. Sahanei et al. reported finding an AHV in eight of 44 livers with hepatic neoplasms using MDCT (Sahani et al., 2002). In studies using MRI, $\mathrm{Ng}$ reported that an AHV was present in 34 of 62 pediatric patients ( $\mathrm{Ng}$ et al.), and Lee et al. reported an AHV in 43 (49\%) of 87 patients (Cha et al., 1995). Using ultrasound, Makuuchi et al. reported that an AHV was present in 27 of 269 patients and Cheng et al. (1997) reported the presence of an AHV in 72 of 400 normal livers. Our study showed the presence of an AHV in $45.6 \%$ of 360 patients using MDCT. Previous reports using helical CT or MDCT showed a similar finding. However, our study showed a higher incidence than the studies that used ultrasound and a slightly lower incidence than studies that used MRI.

Our study showed that $56.7 \%$ of the AHVs were larger than $5 \mathrm{~mm}$ in diameter (93/164), an important finding for preoperative evaluation. According to previous reports on significant surgical AHVs, An et al reported an AHV in 9 (38\%) of 24 liver grafts (10) and Promfret et al. reported a significant AHV in $67 \%$ of 66 potential donors using 3dimentional helical CT.

There have been only a few studies reporting on the morphology of the drainage of the major hepatic veins into the IVC. According to our study, the most common morphology of the IRHV was a single main trunk entering the IVC without tributaries, observed in $58.5 \%$ (96/164) of patients, the second most common was two main trunks with a V-shape at the IRHV-caval confluence observed in $19.5 \%$ (14/164) of the patients, and the third most common was two trunks entering the IVC separately, seen in $17.0 \%$ of the patients. The most common morphology of the MRHV was a single trunk entering the IVC (18 patients) and the second most common was a trunk with tributaries (three patients).

To our knowledge, factors that predict the presence of AHVs have not been reported. Based on a previous study reporting that the area drained by the RHV is inversely proportional to the area drained by the AHV (van Leeuwen et al., 1994), as well as our assumption that patients with a smaller RHV compared to the MHV will show a higher incidence of AHV, we compared the average of the MHV/ $\mathrm{RHV}$ ratio of the group with AHV to the group without AHV. As a result, there was a statistically significant difference between the two groups. The odds that an AHV will be present was 8.05 times higher in the MHV/RHV > 1 group than the MHV/RHV $<1$ group. 
The possibility that an AHV will be present was significantly higher when the diameter of the RHV was smaller than the diameter of the MHV ( $<<0.001)$. It is our thought that as the diameter of the RHV becomes smaller the hepatic venous drainage steadily drains through the AHV instead of through the RHV. If the diameter of the RHV is smaller than that of the MHV, it is prudent to thoroughly examine for the presence of an AHV.
In conclusion, MDCT can provide important information on the presence and morphology of the AHV. The AHV is a common hepatic vascular variant $(45.6 \%)$ which may demonstrate variable morphology. The most common morphology of the IRHV was a single main trunk, followed by two main trunks with a V-shape and two trunks entering the IVC separately. The likelihood of an AHV being present was significantly higher when the diameter of the RHV was smaller than that of the MVH.

KIM, H. S.; LEE, C. H.; KIM, S. H.; KIM, J. W.; PARK, C. M. \& YEOM, S. K. Predicción de la presencia de una vena hepática accesoria mediante tomografía computarizada abdominal. Int. J. Morphol., 35(1):21-25, 2017.

RESUMEN: Se ha informado de la incidencia de la detección de la vena hepática accesoria (VHA) mediante RM o TC. Sin embargo, estudios previos tenían un tamaño muestral pequeño o solo informaban sobre la incidencia de variantes de las venas hepáticas. Hasta donde sabemos, no ha habido ningún informe previo que evalúe los factores predictivos de la presencia de una VHA. El objetivo del estudio fue evaluar la incidencia y morfología de la vena hepática accesoria (VHA) mediante tomografía computarizada multidetector (TCMD) e investigar los factores que pueden ser útiles para predecir la presencia de un VHA. Se evaluaron 360 pacientes que se sometieron a TCMD abdominal. Se investigó si la VHA estaba presente y se evaluó la frecuencia de VHA mayores de $5 \mathrm{~mm}$ de diámetro. Se clasificó la morfología del VHA que drenaba en la vena cava inferior (VCI). Además, se examinaron los factores que predijeron la presencia de una VHA mediante la comparación del diámetro de la vena hepática media (VHM) y la vena hepática derecha (VHD). Se identificó un VHA en 164 de los 360 pacientes (45,6\%). Entre las 164 VHA, el 56,7\% tenía más de $5 \mathrm{~mm}$ de diámetro. Las morfologías más frecuentes del VHD inferior fueron un tronco principal único $(58,5 \%)$, seguido por dos troncos principales con forma de V (19,5\%) y dos troncos que drenaban en la VCI por separado (17,0\%). La posibilidad de que una VHA esté presente fue significativamente mayor cuando el diámetro de la VHD era menor que la de la VHM. La MDCT puede proporcionar información importante sobre la incidencia de la VHA y su morfología. La posibilidad de que un VHA estuviera presente era significativamente mayor cuando el diámetro del VHD era menor que la VHM.

PALABRAS CLAVE: Vena hepática accesoria; TCMD; Hígado; Vena hepática.

\section{REFERENCES}

Cha, S. H.; Park, C. M.; Cha, I. H.; Lee, C. H. \& Rho, T. S.Accessory hepatic vein: MR imaging. J. Korean Radiol. Soc., 33(4):595-8, 1995.

Cheng, Y. F.; Huang, T. L.; Chen, C. L.; Chen, T. Y.; Huang, C. C.; Ko, S. F.; Yang, B. Y. \& Lee, T. Y. Variations of the middle and inferior right hepatic vein: application in hepatectomy. J. Clin. Ultrasound, 25(4):17582, 1997.

Erbay, N.; Raptopoulos, V.; Pomfret, E. A.; Kamel, I. R. \& Kruskal, J. B. Living donor liver transplantation in adults: vascular variants important in surgical planning for donors and recipients. A. J. R. Am. J. Roentgenol., 181(1):109-14, 2003.

Guiney, M. J.; Kruskal, J. B.; Sosna, J.; Hanto, D. W.; Goldberg, S. N. \& Raptopoulos, V. Multi-detector row CT of relevant vascular anatomy of the surgical plane in split-liver transplantation. Radiology, 229(2):4017, 2003.

Inomata, Y.; Uemoto, S.; Asonuma, K. \& Egawa, H. Right lobe graft in living donor liver transplantation. Transplantation, 69(2):258-64, 2000.

Makuuchi, M.; Hasegawa, H.; Yamazaki, S.; Bandai, Y.; Watanabe, G. \& Ito, T. The inferior right hepatic vein: ultrasonic demonstration. Radiology, 148(1):213-7, 1983.

Marcos, A.; Ham, J. M.; Fisher, R. A.; Olzinski, A. T. \& Posner, M. P. Surgical management of anatomical variations of the right lobe in living donor liver transplantation. Ann. Surg., 231(6):824-31, 2000.

Ng, Y. Y.; Finn, J. P. \& Hall-Craggs, M. A. Inferior right hepatic veins: MR assessment of prevalence and potential clinical significance in children. Pediatr. Radiol., 20(8):605-7, 1990.

Orguc, S.; Tercan, M.; Bozoklar, A.; Akyildiz, M.; Gurgan, U.; Celebi, A.; Nart, D.; Karasu, Z.; Icoz, G.; Zeytunlu, M.; Yuzer, Y.; Tokat, Y. \& Kilic, M. Variations of hepatic veins: helical computerized tomography experience in 100 consecutive living liver donors with emphasis on right lobe. Transplant Proc., 36(9):2727-32, 2004.

Pomfret, E. A.; Pomposelli, J. J.; Lewis, W. D.; Gordon, F. D.; Burns, D. L.; Lally, A.; Raptopoulos, V. \& Jenkins, R. L. Live donor adult liver transplantation using right lobe grafts: donor evaluation and surgical outcome. Arch. Surg., 136(4):425-33, 2001.

Sahani, D.; Saini, S.; Pena, C.; Nichols, S.; Prasad, S. R.; Hahn, P. F.; Halpern, E. F.; Tanabe, K. K. \& Mueller, P. R. Using multidetector CT for preoperative vascular evaluation of liver neoplasms: technique and results. A. J. R. Am. J. Roentgenol., 179(1):53-9, 2002.

van Leeuwen, M. S.; Fernandez, M. A.; van Es, H. W.; Stokking, R.; Dillon, E. H. \& Feldberg, M. A. Variations in venous and segmental anatomy of the liver: two- and three-dimensional MR imaging in healthy volunteers. A. J. R. Am. J. Roentgenol., 162(6):1337-45, 1994.

\author{
Corresponding author: \\ Suk Keu Yeom, M.D. \\ Department of Radiology \\ Korea University Ansan Hospital,123 Jeokgeum-ro \\ Danwon-gu, Ansan-si, Gyeonggi-do, 15355 \\ KOREA
}

Email: pagoda20@gmail.com

Received: 06-07-2016

Accepted: 07-09-2016 